\title{
Kinetic characterization of sporulation in Streptomyces albidoflavus SMF301 during submerged culture
}

\author{
Yong Taik Rho and Kye Joon Lee
}

Author for correspondence: Kye Joon Lee. Tel: +822880 6705. Fax: + 8228829285.

Department of Microbiology and Research Centre for Molecular Microbiology, Seoul National University, Seoul 151-742, Korea

\begin{abstract}
We report the first quantitative analysis of the relationship between environmental changes and sporulation of a streptomycete, Streptomyces albidoflavus SMF301, in submerged culture. A chemically defined medium was constructed for sporulation, over $10^{9}$ spores $\mathrm{ml}^{-1}$ being formed in the submerged batch culture. Kinetic parameters calculated from batch and chemostat cultures showed that specific submerged spore formation rate $\left(q_{\text {spo }}\right)$ was inversely related to the specific mycelial growth rate $(\mu)$. The optimum growth rate for submerged spore formation was $0.05 \mathrm{~h}^{-1}$, when the maximum value of $q_{\text {spo }}$ was $1.0 \times 10^{6}$ spores $\mathrm{g}^{-1} \mathrm{~h}^{-1}$. The turnover rate of biomass at maximum growth yield was $0.029 \mathrm{~h}^{-1}$, when $5.6 \times 10^{6}$ spores were formed from $1 \mathrm{~g}$ mycelium. The present quantitative analysis of submerged spore formation using a controlled system opens the way for biochemical and molecular biological studies related to the morphological differentiation of Streptomyces spp.
\end{abstract}

Keywords: Streptomyces albidoflavus, submerged culture, kinetics of sporulation, differentiation

\section{INTRODUCTION}

Secondary metabolite production (physiological differentiation) in Streptomyces spp. accompanies the formation of spores (morphological differentiation), with both being induced by shift-down of some essential nutrients (Champness, 1988; Champness et al., 1989; Chater, 1984; Demain, 1982). Although most streptomycete-derived antibiotics are produced in submerged liquid cultures, studies on the mechanisms involved in the morphological differentiation of Streptomyces spp. have mostly been carried out on solid medium (Chater, 1989, 1991; Chater et al., 1988, 1989; Tan \& Chater, 1993).

Some species of Streptomyces can sporulate in submerged culture, and this has been physiologically analysed in certain cases (Babcock \& Kendrick, 1988; Kendrick \& Ensign, 1983; Koepsel \& Ensign, 1984; Huber et al., 1987; Ochi, 1987; Daza et al., 1989; Glazebrook et al., 1990). However, the kinetics of sporulation of Streptomyces spp. in response to changes in culture conditions have not yet been thoroughly studied. Hence, adequate conclusions have not been made regarding the quantitative relationship between environmental changes and sporulation in these micro-organisms. In this context, we selected a strain of Streptomyces sp. which produced abundant spores both in submerged culture and on solid media (Shin \& Lee, 1986; Jeong et al., 1988; Rho et al., 1988, 1989). This strain was classified as Streptomyces albidoflavus by numerical analysis of the operating taxonomy unit characters (Williams et al., 1983a, b) using TAXON, an identification probability matrix (Rho et al., 1992). The aerial spores formed on solid medium and submerged spores formed in liquid culture were characterized in terms of their cellular composition and resistance to extreme conditions (Lee \& Rho, 1993). In the work reported here, we evaluated the optimum culture conditions for submerged spore formation and analysed kinetic parameters which help elucidate the quantitative relationship between environmental changes and spore formation.

\section{METHODS}

Micro-organisms and media. The micro-organism used was Strepromyces albidoflavus SMF301 (Rho et al., 1992; Lee \& Rho, 1993). Rich medium consisted of (w/v): $1 \%$ glucose, $0.2 \%$ peptone, $0 \cdot 1 \%$ yeast extract and $0.1 \%$ beef extract, with $1 \cdot 8 \%$ agar for solid cultures. Chemically defined medium contained $(\mathrm{w} / \mathrm{v}): \quad 1-2 \%$ glucose, $0.15 \% \quad \mathrm{NH}_{4} \mathrm{Cl}, 0.013 \% \quad \mathrm{KH}_{2} \mathrm{PO}_{4}$, $0.009 \% \mathrm{Na}_{2} \mathrm{HPO}_{4}, 0.06 \% \mathrm{MgSO}_{4} .7 \mathrm{H}_{2} \mathrm{O}$ and $0.0001 \%$ trace elements $\left(\mathrm{FeSO}_{4} \cdot 7 \mathrm{H}_{2} \mathrm{O}, \mathrm{MnCl}_{2} \cdot 4 \mathrm{H}_{2} \mathrm{O}, \mathrm{CaCl}_{2} .2 \mathrm{H}_{2} \mathrm{O}\right.$ and $\left.\mathrm{ZnSO}_{4} \cdot 7 \mathrm{H}_{2} \mathrm{O}\right)$. The initial $\mathrm{pH}$ of media was adjusted to $7 \cdot 0$ 
before steam sterilization; phosphate and magnesium salts were sterilized separately and added to the medium aseptically.

Strain maintenance and culture conditions. S. albidoflavus SMF301 was maintained by transferring to slopes of the rich agar medium each month and storing at $4{ }^{\circ} \mathrm{C}$. Spores that developed on the rich agar medium were suspended in glycerolrich broth medium and stored at $-70^{\circ} \mathrm{C}$ (Wellington \& Williams, 1978). The frozen spore suspensions (about $10^{9}$ spores $\mathrm{ml}^{-1}$ ) were thawed at ambient temperature and used as inocula. For seed cultures, $1 \mathrm{ml}$ spore suspension was inoculated into $50 \mathrm{ml}$ chemically defined medium in $100 \mathrm{ml}$ baffled flasks and incubated for $3 \mathrm{~d}$ at $28^{\circ} \mathrm{C}$ on a rotary shaking incubator $(150$ r.p.m.). The seed cultures were inoculated into 21 chemically defined medium in jar fermenters (model KFC-5, Korea Fermentor Co.) for batch cultures. Culture temperarure was maintained at $28^{\circ} \mathrm{C}$, and $\mathrm{pH}$ was controlled at 7.0 by automatic addition of $1 \mathrm{M} \mathrm{HCl}$ and $1 \mathrm{M} \mathrm{NaOH}$. In all the batch culture experiments (Figs 1-4), aeration was controlled at 1.0 vol. vol. ${ }^{-1} \min ^{-1}$ (v.v.m.) and agitation speed was 500 r.p.m.; this maintained dissolved oxygen tension above $20 \%$ saturation. To commence chemostat operation, a standardized procedure was used in which the culture was grown batch-wise for $48 \mathrm{~h}$, after which the chemostat operation commenced at the desired dilution rate. The medium was metered into the fermenter by a peristaltic pump. Culture temperature and $\mathrm{pH}$, aeration and agitation speed were the same as for batch cultures. A steady-state condition was assumed to have been obtained when three samples over a period of two to three times the mean residence times showed no significant change in any of the measured parameters.

Analysis of growth, spore formation and chemical change. Biomass, including mycelium and spores, in submerged culture was harvested by centrifugation at $15000 \mathrm{~g}$ for $10 \mathrm{~min}$ and washed twice with physiological saline solution and once with distilled water. The washed cells were dried at $100{ }^{\circ} \mathrm{C}$ for $12 \mathrm{~h}$ and the cell dry weight determined. The number of spores formed in submerged cultures was counted as follows. Culture broth $(5 \mathrm{ml})$ was sonicated for $5 \mathrm{~min}$ at $100 \mathrm{~W}$ using a soric desmembrator (model 300, Fisher). The sonicated cell suspension $(0.5 \mathrm{ml})$ was mixed gently with $0.1 \mathrm{M} \mathrm{HCl}(4.5 \mathrm{ml})$ and the mixtures were allowed to stand for $5 \mathrm{~min}$ before diluting in physiological saline and spreading on rich agar medium. Colony counts were made after $4 \mathrm{~d}$ incubation at $28{ }^{\circ} \mathrm{C}$ to give initial spore numbers (Lee \& Rho, 1993). The concentration of reducing sugars in the cell-free culture broth was determined using the dinitrosalicylic acid reagent of Miller (1959). The concentration of ammonium ions was analysed with a specific ion analyser (model EA940, Orion Research).

Analysis of kinetic parameters. The data from chemostat cultures were analysed in terms of various kinetic parameters, namely specific mycelial growth rate $(\mu)$, specific ammonium ion uptake rate $\left(q_{\mathrm{amn}}\right)$, specific glucose uptake rate $\left(q_{\mathrm{glu}}\right)$, and specific spore formation rate $\left(q_{\mathrm{spo}}\right)$. Kinetic parameters in chemostat cultures were calculated as follows: $\mu=D$, where $D$ is the dilution rate $\left(\mathrm{h}^{-1}\right) ; q_{\mathrm{glu}}=D\left(s_{0}-\bar{s}\right) / \bar{x}$, where $s_{0}$ is the corcentration of glucose in the medium, $\bar{s}$ is the steady-state concentration of glucose $\left(\mathrm{gl}^{-1}\right)$, and $\bar{x}$ is the steady-state concentration of biomass $\left(\mathrm{g} \mathrm{l}^{-1}\right) ; q_{\mathrm{amn}}=D\left(n_{0}-\bar{n}\right) / \bar{x}$, where $n_{0}$ is the concentration of ammonium ions in the medium, and $\bar{n}$ is the steady-state concentration of ammonium ions $\left(\mathrm{gl}^{-1}\right)$; $q_{\text {spo }}=D(\bar{p}) / \bar{x}$, where $\bar{p}$ is the steady-state number of spores; $Y_{\mathrm{spo} / \mathrm{x}}=\bar{p} / \bar{x} ; Y_{\mathrm{x} / \mathrm{glu}}=\bar{x} /\left(s_{0}-\bar{s}\right)$. Maintenance energy coefficient $\left(m_{\mathrm{s}}\right)$ and biomass turnover rate $(a)$ were calculated from the following equations: $q_{\mathrm{glu}}=\mu / Y_{\mathrm{x} / \mathrm{s}}^{\max }+m_{\mathrm{s}}$, and $a=m_{\mathrm{s}} Y_{\mathrm{x} / \mathrm{s}}^{\max }$, as given by Pirt (1975).

Chemicals, reagents and reproducibility. Lysozyme, NTG and amino acids were purchased from Sigma. All other chemicals were of reagent grade. Each experiment was repeated three times and the mean values are given.

\section{RESULTS}

\section{Optimum culture conditions for mycelial growth and submerged spore formation}

S. albidoflavus SMF301 grew well in the chemically defined medium containing glucose, fructose, maltose, starch or mannitol, but not in that containing sucrose, lactose or myo-inositol (Rho et al., 1992). Since glucose was the best energy and carbon source, the effects of glucose concentration on mycelial growth and spore formation in submerged batch culture were evaluated. Mycelial growth and sporulation in submerged culture was not repressed by glucose at concentrations of up to $40 \mathrm{~g} \mathrm{l}^{-1}$ when the culture $\mathrm{pH}$ was not controlled (Fig. 1a). However, repression was observed with higher concentrations of glucose (Fig. 1a). Repression at high concentrations of glucose was not evident when the culture $\mathrm{pH}$ was
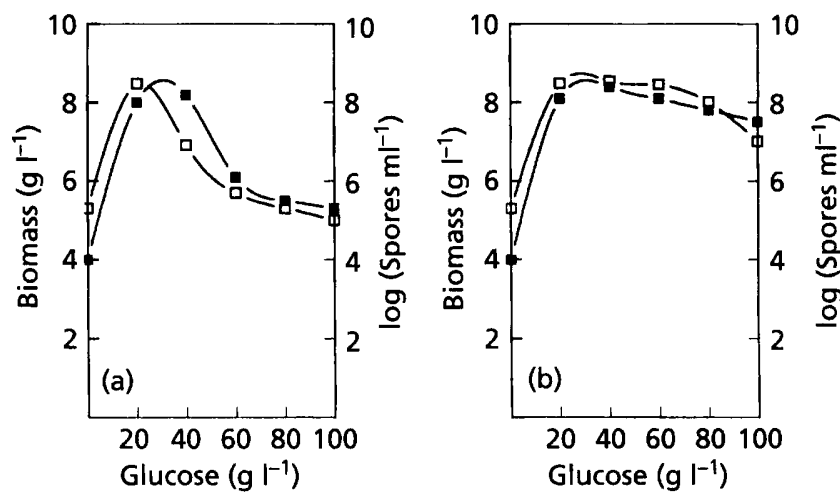

Fig. 1. Effects of glucose concentration on the formation of biomass ( $\square$ ) and spores ( $\square$ ) in batch cultures of $S$. albidoflavus SMF301. (a) Initial culture $\mathrm{pH}$ was adjusted to 7.0 at the beginning of incubation, but was not controlled thereafter; (b) culture $\mathrm{pH}$ was maintained at 7.0 throughout the incubation period. The results shown were from $5 \mathrm{~d}$ cultures.

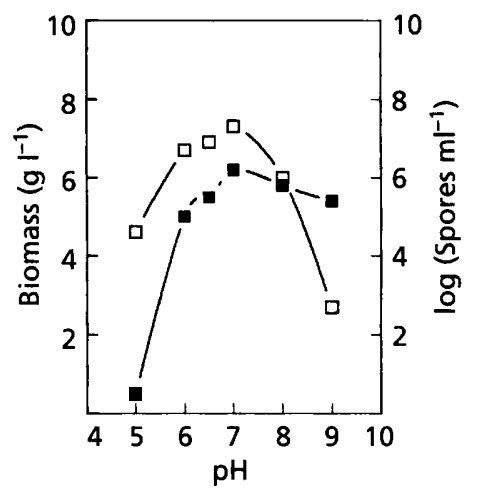

Fig. 2. Effects of culture pH on the formation of biomass ( $\square$ and spores ( $\square$ ) in batch cultures of S. albidoflavus SMF301. The results shown were from $5 \mathrm{~d}$ cultures. 

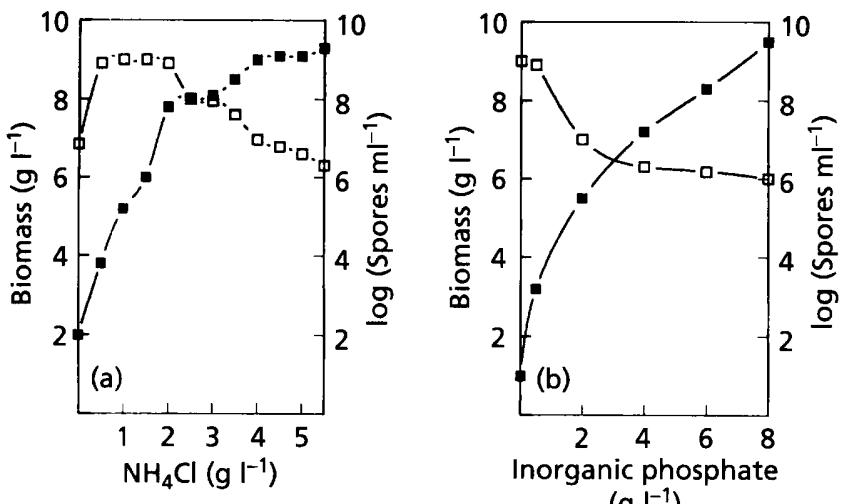

$\left(\mathrm{g}^{-1}\right)$

Fig. 3. Effects of the concentration of (a) ammonium ions and (b) inorganic phosphate on the formation of biomass ( $\square$ ) and spores $(\square)$ in batch cultures of S. albidoflavus SMF301. The results shown were from $5 \mathrm{~d}$ cultures.

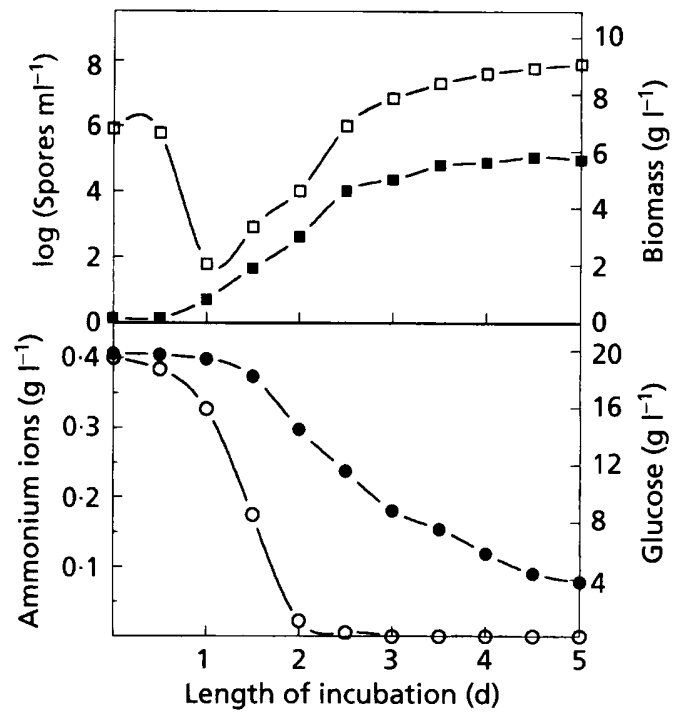

Fig. 4. Changes in the concentration of ammonium ions $(O)$, glucose (O), biomass ( $\square$ ) and spores $(\square)$ in batch cultures of S. albidoflavus SMF301.

maintained at $7 \cdot 0$ (Fig. 1b). Since the culture $\mathrm{pH}$ became acid at higher glucose concentrations, the effects of culture $\mathrm{pH}$ on mycelial growth and spore formation were evaluated. The culture $\mathrm{pH}$ was maintained at a set point between 5 and 9 by the automatic addition of $1 \mathrm{M} \mathrm{HCl}$ or $1 \mathrm{M} \mathrm{NaOH}$. It was found that the optimum $\mathrm{pH}$ for mycelial growth and spore formation was $7 \cdot 0$, but spore formation was more clearly repressed by alkaline culture $\mathrm{pH}$ than was mycelial growth (Fig. 2).

Although mycelial growth increased steadily with an increase in ammonium ion concentration, submerged spore formation was optimum at $1.5 \mathrm{~g} \mathrm{NH}_{4} \mathrm{Cl} \mathrm{l}^{-1}$ (Fig. 3a). Mycelial growth also increased with increasing inorganic phosphate concentration, but submerged spore formation was optimum with $2.5 \mathrm{mg}$ inorganic phosphate $\mathrm{l}^{-1}$ (Fig. 3b). The effects of other mineral salts on mycelial

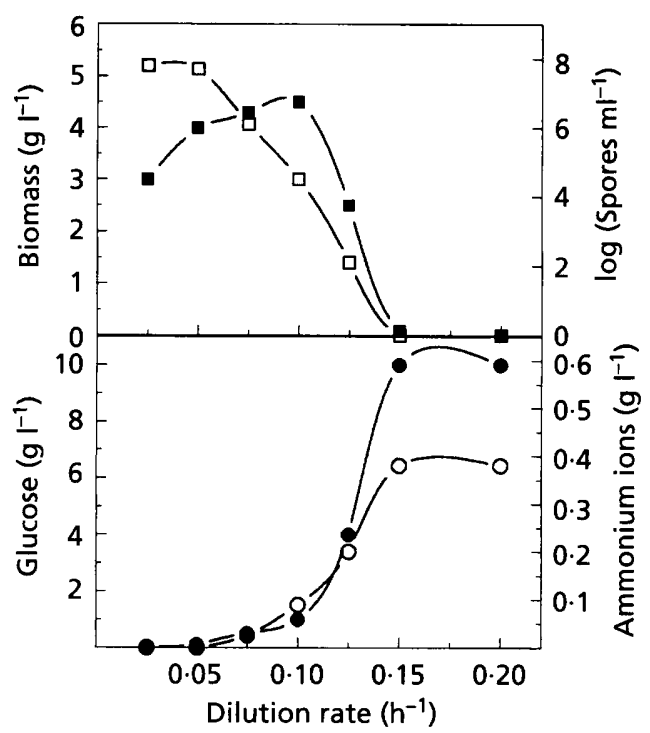

Fig. 5. Steady-state values of ammonium ions (O), glucose (O), biomass $(\square)$ and submerged spores $(\square)$ in glucose- and $\mathrm{NH}_{4} \mathrm{Cl}$ limited chemostats of S. albidoflavus SMF301.

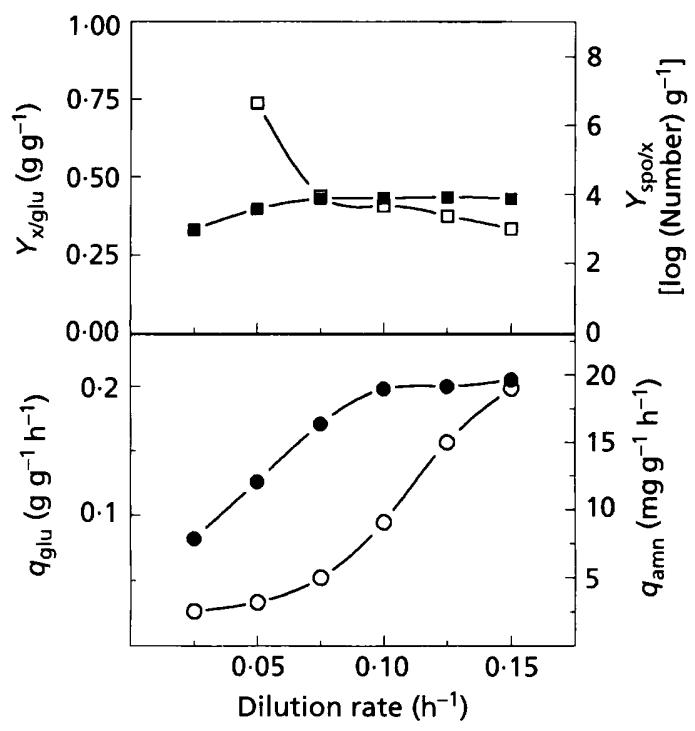

Fig. 6. Effect of specific growth rate on $q_{\text {amn }}(O), q_{g l u}(0), Y_{x / s}$ (G) and $Y_{\text {spo/x }}(\square)$ in glucose- and $\mathrm{NH}_{4} \mathrm{Cl}$-limited chemostats of S. albidoflavus SMF301.

growth and submerged spore formation were evaluated, but the effects were not significant. The optimum temperature for mycelial growth and submerged spore formation was $25-30{ }^{\circ} \mathrm{C}$ (data not shown).

\section{Kinetic parameters for mycelial growth and submerged spore formation}

The changes in concentration of glucose, ammonium ions, biomass and submerged spores in a batch culture using the chemically defined medium are shown in Fig. 4. 

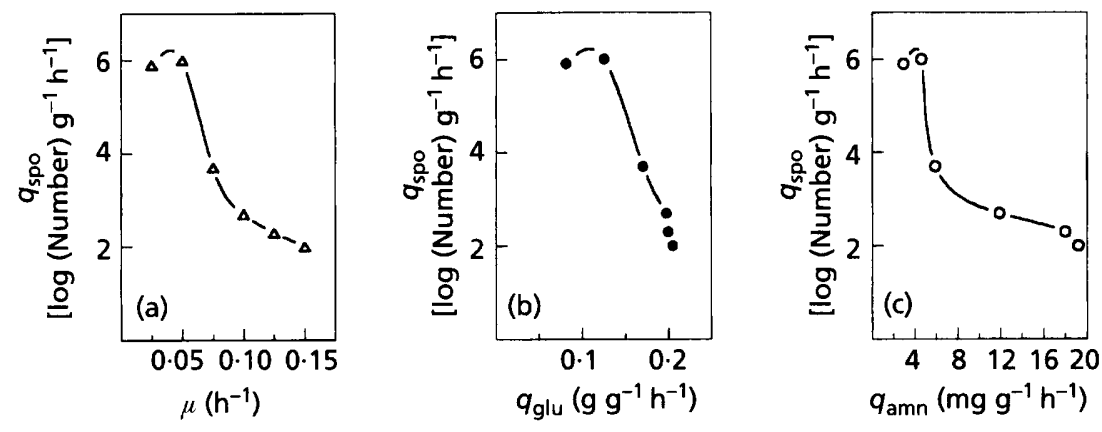

Fig. 7. Relationship between (a) $\mu$ and $q_{\text {spo }}$
(b) $q_{\text {glu and } q_{\text {spo' }} \text { and (c) } q_{\text {amn }} \text { and } q_{\text {spo of }}}$
S. albidoflavus SMF 301 in chemostat culture.

The number of submerged spores decreased with the initiation of mycelial growth, indicating germination of spores. Mycelial growth revealed a typical batch culture pattern, entering stationary phase when ammonium ions were completely utilized. However, the formation of spores was evident when the residual concentration of glucose was still relatively high.

Since the formation of submerged spores appeared to be closely related to the concentration of ammonium ions, experiments with ammonium-ion-limited chemostats were carried out in order to evaluate more precisely the relationship between the kinetic parameters. The steadystate values of glucose, ammonium ions, biomass and submerged spores are shown in Fig. 5. The steady-state concentrations of biomass decreased at lower dilution rates (below $0 \cdot 1 \mathrm{~h}^{-1}$ ), but submerged spore formation was inversely related to dilution rate (specific growth rate). The optimum dilution rates were $0 \cdot 1 \mathrm{~h}^{-1}$ for mycelial growth and $0.05 \mathrm{~h}^{-1}$ for submerged spore formation.

Kinetic parameters calculated from the steady-state ciata of the chemostat culture are shown in Fig. 6. Specific ammonium ion uptake rate $\left(q_{\mathrm{amn}}\right)$ and specific glucose uptake rate $\left(q_{\mathrm{glu}}\right)$ increased as the dilution rate increased. The maximum value of $q_{\text {glu }}$ was $0.2 \mathrm{~g} \mathrm{~g}^{-1} \mathrm{~h}^{-1}$ at $0.1 \mathrm{~h}^{-1}$, whereas the maximum value of $q_{\text {amn }}$ was $0.018 \mathrm{~g} \mathrm{~g}^{-1} \mathrm{~h}^{-1}$ at $0 \cdot 15 \mathrm{~h}^{-1}$. The maintenance energy coefficient $\left(m_{\mathrm{s}}\right)$ was calculated to be $0.046 \mathrm{~g} \mathrm{~g}^{-1} \mathrm{~h}^{-1}$ by extrapolating the values of $q_{\mathrm{glu}}$ to zero growth rate. Maximum growth yield $\left(Y_{\mathrm{x} / \mathrm{s}}^{\mathrm{max}}\right.$ ) was calculated to be $0.636 \mathrm{~g} \mathrm{~g}^{-1}$, and the rate of biomass turnover (a) was estimated to be $0.029 \mathrm{~h}^{-1}$. By plotting $q_{\text {spo }}$ against $\mu$ (Fig. 7a), $q_{\text {glu }}$ (Fig. 7b) and $q_{\text {amn }}$ (Fig. $7 \mathrm{c}$ ), it was clear that $q_{\text {spo }}$ was inversely related to all these parameters. The maximum value of $q_{\text {spo }}$ $\left(1.0 \times 10^{6} \mathrm{~g}^{-1} \mathrm{~h}^{-1}\right)$ was obtained at $0.05 \mathrm{~h}^{-1}$, when $5.6 \times 10^{6}$ spores were formed from $1 \mathrm{~g}$ of mycelium.

\section{DISCUSSION}

Differing results have been obtained for the effec: of glucose concentration on the formation of spores in submerged culture of a range of Streptomyces spp. Daza et al. (1989) found that sporulation of several species of Streptomyces in submerged culture was not inhibited by high concentrations of glucose. In contrast, Glazebrook et al. (1990) found that sporulation of Streptomyces venezuelae in submerged culture was repressed by high concentrations of glucose, and that this repression was not merely a secondary result of acid accumulation. The same result was also obtained with Streptomyces griseus (Babcock $\&$ Kendrick, 1988). In addition, cellular differentiation of Streptomyces coelicolor A3(2) in surface culture was inhibited by high concentrations of glucose (Chater et al., 1988).

In the present experiments, we found that sporulation of S. albidoflavus SMF301 in submerged culture was $\mathrm{pH}$ dependent, with an optimum at $7 \cdot 0$, and that spore formation was not repressed by glucose up to $80 \mathrm{~g} \mathrm{l}^{-1}$ when the culture $\mathrm{pH}$ was maintained at $7 \cdot 0$. Therefore, it was concluded that sporulation of S. albidoflavus SMF301 in submerged culture is more affected by culture $\mathrm{pH}$ than by high concentrations of glucose; however, the molecular mechanism remains to be elucidated.

It has been reported that sporulation of $S$. griseus in submerged culture is initiated by ammonium ion starvation (Kendrick \& Ensign, 1983), and that an excess of nitrogen is inhibitory to submerged spore formation in $S$. venezuelae (Glazebrook et al., 1990). We found that mycelial growth in submerged culture of $S$. albidoflavus SMF301 was enhanced by higher concentrations of ammonium ions or inorganic phosphate, whereas sporulation was repressed significantly by these conditions. Our data indicated that nitrogen or phosphate starvation influenced the shift from mycelial growth to submerged spore formation.

Prior to the present investigation, kinetic studies on the sporulation of Streptomyces spp. in submerged culture had not been reported, although the physiological analysis of sporulation of several species of Streptomyces in submerged culture has been carried out (Babcock \& Kendrick, 1988; Kendrick \& Ensign, 1983; Koepsel \& Ensign, 1984; Huber et al., 1987; Ochi, 1987; Daza et al., 1989; Glazebrook et al., 1990). From our batch and continuous culture kinetic analysis, it was very clear that the specific rate of formation of spores was inversely related to the specific growth rate $(\mu)$, and that $q_{\text {spo }}$ was optimum $\left(1.0 \times 10^{6}\right.$ spores $\left.\mathrm{g}^{-1} \mathrm{~h}^{-1}\right)$ when $\mu$ was $0.05 \mathrm{~h}^{-1}$. The rate of biomass turnover was $0.029 \mathrm{~h}^{-1}$, when $5.6 \times 10^{6}$ spores was formed from $1 \mathrm{~g}$ of mycelium.

This study is the first attempt to analyse quantitatively the relationship between mycelial growth and spore formation of Streptomyces spp. in submerged culture. The strain used produced abundant spores in submerged culture compared to other species of Streptomyces. Such quantitative analysis in controlled, submerged liquid 
culture using a simple, chemically defined medium offers a system in which to elucidate the biochemical and molecular biological basis of morphological differentiation in Streptomyces spp.

\section{ACKNOWLEDGEMENTS}

We should like to thank Professor K. F. Chater, Professor M. Goodfellow and Dr M. E. Bushell for discussions throughout the study, Mr J. A. Foley for proofreading the manuscript, and Mr S. G. Kang for computer analysis. This work was supported by a grant from the SRC (Research Centre for Molecular Microbiology) supported by the Korea Science and Engineering Foundation (KOSEF).

\section{REFERENCES}

Babcock, M. J. \& Kendrick, K. E. (1988). Cloning of DNA involved in sporulation of Streptomyces griseus. J Bacteriol 170, 2802-2808.

Champness, W. C. (1988). New loci required for Streptomyces coelicolor morphological and physiological differentiation. J Bacteriol 170, $1168-1174$.

Champness, W. C., Adamidis, T. \& Riggle, P. E. (1989). Developmental genes and antibiotic biosynthesis. In Genetics and Molecular Biology of Industrial Microorganisms, pp. 108-112. Edited by C. L. Hershberger, S. W. Queener \& G. Hegeman. Washington, DC: American Society for Microbiology.

Chater, K. F. (1984). Morphological and physiological differentiation in Streptomyces. In Microbial Development, pp. 89-115. Edited by R. Losick \& L. Shapiro. Cold Spring Harbor, NY : Cold Spring Harbor Laboratory.

Chater, K. F. (1989). Sporulation in Streptomyces. In Regulation of Prokaryotic Development, pp. 277-299. Edited by I. Smith, R. A. Slepecky \& P. Setlow. Washington, DC: American Society for Microbiology.

Chater, K. F. (1991). Sap, hydrophobins and aerial growth. Curr Biol 1, 318320 .

Chater, K. F., Lawlor, E. J., Mendez, C., Bruton, C. J., Davis, N. K., Plaskitt, K., Guthrie, E. P., Daly, B. L., Baylis, H. A. \& Trong, K. V. (1988). Gene expression during Streptomyces development. In Biology of Actinomycetes' 88 . Proceedings of the 7 th International Symposium for Biology of Actinomycetes, pp. 64-70. Edited by Y. Okami. Tokyo: Japan Scientific Societies Press.

Chater, K. F., Bruton, C. J., Plaskitt, K. A., Buttner, M. J., Mendez, C. \& Helmann, J. (1989). The developmental fate of Streptomyces coelicolor hyphae depends crucially on a gene product homologous with motility sigma factor of Bacillus subtilis. Cell 59, 133-143.

Daza, A., Martin, J. F., Dominguez, A. \& Gil, J. A. (1989). Sporulation of several species of Streptomyces in submerged culture after nutritional downshift. J Gen Microbiol 135, 2483-2491.

Demain, A. L. (1982). Catabolic regulation in industrial microbiology. In Overproduction of Microbial Products, pp. 3-20. Edited by V. Krumphanzl, B. Sikya \& Z. Vanek. New York: Academic Press.
Glazebrook, M. A., Doull, J. L., Stuttard, C. \& Vining, L. C. (1990). Sporulation of Streptomyces venezuelae in submerged cultures. J Gen Microbiol 136, 581-588.

Huber, F. M., Piper, R. L. \& Mertz, F. P. (1987). Sporulation of Streptomyces roseosporus in submerged culture. J Ind Microbiol 2 , 235-241.

Jeong, B. C., Shin, H. S. \& Lee, K. J. (1988). Relationship between sporulation and synthesis of alkaline protease in a Streptomyces sp. Korean J Microbiol 26, 355-361.

Kendrick, K. E. \& Ensign, J. C. (1983). Sporulation of Streptomyces griseus in submerged culture. $J$ Bacteriol 155, 357-366.

Koepsel, R. \& Ensign, J. C. (1984). Microcycle sporulation of Streptomyces viridochromogenes. Arch Microbiol 140, 9-14.

Lee, K. J. \& Rho, Y. T. (1993). Characteristics of spores formed by surface and submerged cultures of Streptomyces albidoflavus SMF301. J Gen Microbiol 139, 3131-3137.

Miller, G. L. (1959). Use of dinitrosalycilic acid reagent for determination of reducing sugar. Anal Chem 31, 426-428.

Ochi, K. (1987). Changes in nucleotide pools during sporulation of Streptomyces griseus in submerged culture. J Gen Microbiol 133, $2787-2795$.

Pirt, S. J. (1975). The Principles of Microbe and Cell Cultivation. Oxford: Blackwell Scientific Publications.

Rho, Y. T., Jeong, B. C. \& Lee, K. J. (1988). Molecular cloning of alkaline protease in Streptomyces spp. and optimization of fermentation: role of alkaline protease in the cell differentiation. In Proceedings of the 3rd Conference on Molecular Biology \& Genetic Engineering, pp. 57-62. Seoul: Korean Society of Molecular Biology.

Rho, Y. T., Kim, J. W. \& Lee, K. J. (1989). Regulation of alkaline protease biosynthesis in Streptomyces spp.: effects of culture environments on gene expression. In Proceedings of the 4 th Conference on Molecular Biology \& Genetic Engineering, pp. 91-94. Seoul: Korean Society of Molecular Biology.

Rho, Y. T., Kim, H. T., Oh, K. H., Kang, H. I., Ward, A. C., Goodfellow, M., Hah, Y. C. \& Lee, K. J. (1992). Numerical identification of a Streptomyces strain producing spores in submerged culture. Korean J Microbiol 30, 278-285.

Shin, H. S. \& Lee, K. J. (1986). Regulation of extracellular alkaline protease biosynthesis in a strain of Streptomyces spp. Korean $J$ Microbiol 24, 32-37.

Tan, H. \& Chater, K. F. (1993). Two developmentally controlled promoters of Streptomyces coelicolor A3(2) that resemble the major class of mobility-related promoters in other bacteria. J Bacteriol 175, 933-940.

Wellington, E. M. H. \& Williams, S. T. (1978). Preservation of actinomycete inoculum in frozen glycerol. Microbios Lett 6, 151-157.

Williams, S. T., Goodfellow, M., Alderson, G., Wellington, E. M. H., Sneath, P. H. A. \& Sackin, M. (1983a). Numerical classification of Streptomyces and related genera. J Gen Microbiol 129, 1743-1813.

Williams, S. T., Goodfellow, M., Wellington, E. M. H., Vickers, J. C., Alderson, G., Sneath, P. H. A., Sackin, M. \& Mortimer, A. M. (1983b). A probability matrix for the identification of some streptomycetes. J Gen Microbiol 129, 1815-1830.

Received 30 July 1993; revised 23 March 1994; accepted 25 March 1994 